\title{
Laparoscopic Hernia Repair in Neonates, Infants and Children
}

\author{
Yaron Armon and Dan Arbell \\ Department of Pediatric Surgery, Hadassah-Hebrew University Hospital, Jerusalem
}

Israel

\section{Introduction}

Inguinal hernia is a very common condition in children 1-3 and adults and is the most common operation performed on children 4 (other than ritual circumcision). Since the "classic" open repair was introduced, it has become the standard operation for hernias, with very few controversies: whether the surgeon should perform only a herniotomy or reinforce the repair, whether a contralateral groin exploration be performed, and so forth. The operation is quick, safe, 5 and can be done in an outpatient setting with anesthesia via a laryngeal mask. The recurrence rate is acceptable, $1 \%-5 \% 6-8$, depending on the expertise of the surgeon, the child's' age and concomitant diseases.

The advent of laparoscopy has changed many dogmas in all fields of surgery, pediatric hernia repair included. Many operations that were considered as "gold standard" are being challenged by the laparoscopic approach and the new technologies it has brought with it. In the specific case of pediatric hernia repair, another challenge on the open technique was introduced by the development of fertility clinics and the higher than expected incidence of azoospermia due to an injury to the vas deferens during bilateral hernia repairs 9-10,14. Therefore, two major applications of laparoscopy were introduced to hernia repair in children. The first, performing an intra-operative diagnostic laparoscopy for diagnosing a non-symptomatic contralateral hernia during open hernia surgery. The second, performing a laparoscopic repair. During the forthcoming chapter, the merits, disadvantages and techniques of both procedures will be reviewed.

\section{Diagnostic laparoscopy during open pediatric hernia repair}

The incidence of a contralateral, asymptomatic groin hernia in children is not well defined. Reports vary from $10 \%$ to $60 \%$, depending on prematurity of the child, gendre and side 11 12. Also, there is no consensus on whether a patent processus vaginalis is considered a hernia for practical purposes, i.e. whether it should be repaired or not.

It is established that the premature have a higher incidence of bilateral hernias 13, and that bilateral hernias are commoner in females with a left sided hernia 11-12. Until laparoscopy developed, there was controversy regarding whether a contralateral groin exploration should be performed and to whom. On the one hand, an exploration ensured a diagnosis during one operation and anesthesia, an option that carries many advantages to the patient 
and the parents. On the other hand, most of these explorations performed on children above the age of 1 year were negative, doubling the operating and anesthetic time and risking a bilateral vas deferens injury with future infertility 14 . Therefore, most surgeons had loosely based criteria on whom the exploration was performed. Since a hernia can be very easily and accurately diagnosed from within the peritoneum, introduction of a laparoscope during the operation seemed like a natural answer for the question.

\section{Technique}

During the operation for a hernia, the hernia sac is separated from the spermatic cord and isolated. Before ligating the sac, a $5 \mathrm{~mm}$ port is introduced through the sac and a $70^{\circ}$ scope is passed into the peritoneum. The patient is put head down and most times there is need for mild insufflation up to pressure of $6-8 \mathrm{mmHg}$ of the abdominal cavity in order view the contralateral inguinal area. Care must be taken to avoid injury to the hernia sac while introducing the port, and the sac opening has to be secured to the port in order to avoid air escaping around it. We recommend placing vessel loops or other markers around the elements of the cord in order to ease their identification after the laparoscopy and continue with the hernia repair. It is also helpful to ensure an empty bladder before the laparoscopy, as it may be difficult to pass a full bladder from this approach, certainly in a small child. If a synchronous hernia is identified, a contralateral open repair is performed after finishing the original side. Our custom is to treat a patent processus as a hernia.

\section{Results}

In our experience, diagnostic trans-inguinal laparoscopy has been accurate in $97 \%$ of the cases. In $2 \%$ there was failure to identify a hernia due to tear of the hernia sac, or inadequate visualization. There were no cases of false positive examinations. In $1 \%$ of the patients the laparoscopy was aborted because the pneumoperitoneum compromised the anesthesia. These results are similar to those reported in the literature.15,16

\section{Advantages}

Diagnostic trans-inguinal laparoscopy provides definite advantages in the accurate diagnosis of a contralateral synchronous hernia during a single anesthesia 15,16. It is easy to learn and is very comfortable for a surgeon that is proficient in the open hernia repair technique. Usually, the pneumoperitoneum required does not preclude anesthesia via a laryngeal mask and does not require paralytic agents.

\section{Disadvantages}

The major disadvantage of this approach is when dealing with a very young or premature baby with a very delicate hernia sac. This is true also for a hernia accompanying an undescended testicle. In these cases, the insertion of the port may easily tear the hernia sac and compromise the ipsilateral repair. Another disadvantage is that in the case of a synchronous hernia, a bilateral open repair is performed with the concomitant risk of bilateral damage to the spermatic cord and infertility. 


\section{Laparoscopic hernia repair}

When challenging a time honored technique in surgery, it is necessary to convince that are major advantages in the newer one. This is certainly true for laparoscopic repair of pediatric hernias, as the open repair is very common, safe, quick and the surgeon is very familiar with the procedure. Therefore, prior to describing the laparoscopic repair, we shall examine the pitfalls of the open one.

1. The subject of synchronous or metachronous contralateral hernia has been discussed in the previous paragraph.

2. Damage to the spermatic cord during hernia repair is an under evaluated topic in surgery. Recent reports in adult surgical literature have enhanced the awareness of spermatic cord injury during hernia repair, mostly those using a mesh graft. Of higher consequence to our discussion are the reports of an increased rate of male infertility following a bilateral hernia repair during early childhood. It is hard to assess the true rate of cord injury during hernia surgery, since the operation is very common, and there has to be a complete bilateral blockade in the vas deferens in order to cause infertility. Yet, the rate of damage is probably higher than previous assessments.

3. Testicular atrophy may be a consequence of an incarcerated hernia with compromised testicular blood supply and may also be due to vascular damage during hernia repair. It is hard for the surgeon to assess the viability of a compromised testicle during a repair, as well as to assess the possibility of vascular damage during the handling of the cord.

4. An open repair during an incarcerated hernia is sometimes cumbersome and tedious. It is often difficult to assess the viability of the organs that were incarcerated, as they tend to spontaneously reduce during anesthesia or at the beginning of surgery. In cases of necrotic bowel, omentum or severe edematous tissues, it becomes a challenge to correctly identify the anatomy to allow for a good repair.

5. Recurrent hernias are rare in the pediatric population, with reports ranging from $0.5 \%$ to $5 \%$, depending on the child's age and maturity. Although rare, every surgeon has to face this challenge every once in a while, and is familiar with the problem of dissecting through scar tissue in order to discern the anatomy.

6. A symptomatic hernia in an undescended testicle is a complex problem. Whilst it is better to wait for 6-12 months before performing orchipexy, sometimes surgical intervention is needed sooner than that. This, of course, may compromise either the hernia repair or the orchipexy.

The laparoscopic approach is supposed to provide an answer to all these issues. First, as discussed previously, laparoscopy provides an excellent visualization of the groin from within the peritoneum, adequately diagnosing a synchronous hernia 15,17 or patent processus vaginalis. Second, since the vas and blood vessels are visualized with precision and are not handled in most laparoscopic repairs, the possibility of cord damage during surgery is reduced. The same goes for vascular compromise of a borderline testicle that suffered from incarceration. When dealing with an incarcerated hernia, laparoscopy allows direct visualization of the reduced incarcerated contents and their viability. It also circumnavigates the problem of anatomical precision in edematous or scarred areas (such as in a recurrent hernia) with a lower complication rate 4. Last, laparoscopy can allow a hernia closure in an undescended testicle without compromising the forthcoming orchipexy. 


\section{Technique}

The child requires endotracheal intubation and anesthesia with paralytic agents in order to allow adequate pneumoperitoneum. A camera port is introduced above the umbilicus, since in very small infants one gains a small but significant space for working in the abdomen. We advocate using the open "Hasson" technique for accessing the peritoneum. After insufflation according to the patient's weight, the patient is put head down and the groin area inspected. The surgeon places himself at the patient's head and his assistant next to him on the side opposite the hernia. Two needle holders are placed on each flank of the patient, about the level of the camera port. Usually, there is no need for a port and the instruments are placed directly into the abdomen. One of the needle holders is inserted with the suture held just above the needle in order to facilitate it's navigation into the abdomen. We utilize nonabsorbable sutures, usually a prolene $0-4$ for reasons that will be discussed later. Shortening the suture to $10-11 \mathrm{~cm}$ with a not at the end may facilitate identification of the suture end, a maneuver that is helpful in small infants where the space is very limited and the suture end might stay outside the abdomen or slip while pulling the strings. A purse string is sutured around and proximal to the hernia opening and tied intra-corporeally, closing the opening. Care should be taken to identify precisely the vas deferens and blood vessels, in order to pass the suture above them and not through or under them. We routinely reinforce the suture with another "Z" suture above the repair. If there is a synchronous hernia, the procedure is repeated on the other side using a new suture. Attention should be given to needle extraction under vision, as the suture may break during the extraction leaving the needle in the abdomen. Performing the operation without the ports reduces the risk of this happening. After completion, the umbilicus is closed along with a concomitant umbilical hernia if there is one. The side entries do not usually require closure.

\section{Technical pitfalls}

In the technique described, there are several technical pitfalls that became apparent as experience grew, and the major problem of the operation became apparent - an increased rate of recurrence, $4 \%-10 \%$ of the cases. Before discussing the proposed solutions for decreasing the recurrence rate, there are several points that should be stressed in the technique.

1. Suture material. Since the hernia sac is not dissected or cut in the aforementioned procedure, care must be taken to use non-absorbable sutures. Part of the recurrence is due to the suture material being absorbed after several months, leaving the hernia sac widely opened as if there was no operation at all. This is indeed the view seen when operating a recurrence either laparoscopically or open. We utilize a prolene suture as it is non-absorbable, has a variety of needle sizes and is very easy to handle. Intracorporeal suturing of prolene requires experience, as the suture material tends to break if improperly handled, and we put a knot at the end to facilitate identification before the suture slips into the tissues.

2. Placement of suture. Many of the patients are small infants that continue to grow after the operation. If the repair is made inside the opening of the hernia sac, the minute residual opening may grow to become a hernia. Care should be taken to place the suture just inside the inguinal ream. This complication is more common in small infants with large inguino-scrotal hernias. 
3. Needle retrieval. When operating small children, it is advisable not to use operating ports but rather to introduce the instruments directly into the abdomen. Three $\mathrm{mm}$ ports do not allow insertion and retrieval of the regular curved needle. The needle tends to lodge in the port opening and disconnect, causing a search for it in the abdomen, sometimes requiring a conversion to a laparotomy for the retrieval. When the instruments are directly inserted, the abdominal wall closes snugly around the instrument with little or no escape of gas. Needle retrieval is easily done by manipulating the needle through the wound. It is always advisable to follow the retrieval with the camera to ensure safety.

4. Pneumoperitoneum and anesthesia. It is very helpful for the surgeon to stand at the head of the operating table when dealing with small children. It is our experience that only with this stance he may achieve the necessary movements in the small space the pediatric abdomen allows. By doing that, he compromises the control the anesthetist has on patient airway and venous lines, which may be critical in infants. It is very important to have the endotracheal tube and venous lines well secured and approachable before starting to prepare the patient, since dislodgement of these may have hazardous consequences.

5. Hernia in an undescended testicle. Infants with a symptomatic hernia in an undescended testicle are always small, less than 6 months of age; otherwise an orchipexy would be performed. In this age group, the testicle may migrate downwards naturally during the months after the repair. This migration may include the repair itself "en block". The parents should be advised that the hernia repair may be a temporary measure for the symptoms until a definite orchipexy is performed at a later age.

6. Direct hernia. A direct hernia is very rare in the pediatric population but should be actively sought after when visualizing the groins. This is easily done when thought of beforehand.

In view of all these pitfalls, it is appropriate to mention that a laparoscopic hernia repair does not greatly compromise a subsequent open repair, as the area is virtually untouched, avoiding the anatomical confusion of the scar tissue when doing a repeat open repair.

\section{Proposed technical improvements}

In view of the higher recurrence rate, several technical improvements have been proposed. These include dissection of the hernia sac with or without disconnection of the distal part, 18 different suture techniques such as percutaneous suturing or "flip-flap" modifications 19,20. There is consensus that the approach in infants should be intra-peritoneal and that there is no need for reinforcement of the repair with foreign materials such as meshes. Most of these modifications are performed in single centers and have not yet passed the time required to prove a definite improvement, though the early reports carry a promise for minimizing recurrence while not significantly augmenting the risks for cord injury or operative time.

\section{Advantages}

There are definite advantages to the laparoscopic hernia repair in children. This approach offers excellent diagnosis of a synchronous hernia or patent processus vaginalis 15,17,21 and 
the repair is performed with minimal handling and potential damage to the spermatic cord. It is very useful for treating incarcerated or recurrent hernias, bypassing the anatomical challenges in these cases 22. After a necessary learning curve, most technical pitfalls can be avoided and operating times shortened to those of the open hernia repair.

\section{Disadvantages}

The laparoscopic approach does require a learning curve 23. Most surgeons feel very comfortable with the open technique and would rather face the challenges of a difficult case such as the incarcerated, recurrent or undescended testicle hernia than learn a completely new technique. Laparoscopy in infants requires a more complex anesthetic setting with facilities and personnel that may be not available in outpatient clinics. Undoubtedly, for the time being, laparoscopic repairs carry a higher recurrence rate 24,25. Although recurrence after laparoscopy is not as challenging as after open repair, this should be weighed against the potential benefits of the approach.

\section{Conclusions}

The advent of laparoscopy has widely changed the scope of pediatric hernia repairs. Whether as a diagnostic or operative tool, the use of laparoscopy is widely gaining popularity as it provides an answer to many dilemmas. Since there are advantages and disadvantages to all approaches, a consensus as to the best approach has not been reached. It seems logical that there is no dogmatic "best" approach for all cases, each case requiring a specific tailoring of the care required. It is still up to the parent to decide what risks are preferred: a metachronous hernia, the risk of future infertility or the increased rate of recurrence. Therefore, it seems wise at this time that a pediatric surgical team be well versed in all approaches in order to combine the advantages to the benefit of the patient.

\section{Reference}

[1] Grosfeld, JL. Current concepts in inguinal hernia in infants and children. World J Surg 1989; 13:506.

[2] Cox J. Inguinal hernia of childhood. Surg Clin North Am 1985; 65:1331-1342.

[3] Hamey M, Johnstone M, Fossard D. Inguinal herniotomy in children: A five year survey. Br J Surg 1985; 72:485-487.

[4] Kapur, P, Caty, MG, Glick, PL. Pediatric hernias and hydroceles. Pediatr Clin North Am 1998; 45:773.

[5] Nagar H. Stitch granulomas following inguinal herniotomy: a 10-year review. J Pediatr Surg 1993;28:1505- 7.

[6] Levitt MA, Ferraraccio D, Arbesman MC, Brisseau GF, Caty MG, Glick PL. Variability of inguinal hernia surgical technique: a survey of North American pediatric surgeons. J Pediatr Surg 2002; 37:745-751

[7] Antonoff MB, Kreykes NS, Saltzman DA, Acton RD American academy of pediatrics section on surgery hernia survey revisited. J Pediatr Surg 2005; 40:1009-1014 
[8] Ein SH, Njere I, Ein A Six thousand three hundred sixty one pediatric inguinal hernias; a 35-year review. J Pediatr Surg 2006; 41:980-986

[9] Sandhu DPS., Osborn DE, and Munson KW. Relationship of azoospermia to inguinal surgery. International Journal of Andrology. 1992;15: 504-506.

[10] Zendejas B, Zarroug AE, Erben YM, Holley CT, Farley DR.Impact of childhood inguinal hernia repair in adulthood: 50 years of follow-up. J Am Coll Surg. 2010 Dec;211(6):762-8

[11] Tackett, LD, Breuer, CK, Luks, FI, et al. Incidence of contralateral inguinal hernia: a prospective analysis. J Pediatr Surg 1999; 34:684.

[12] Miltenburg, DM, Nuchtern, JG, Jaksic, T, et al. Meta-analysis of the risk of metachronous hernia in infants and children. Am J Surg 1997; 174:741.

[13] Rescorla FJ, Grosfeld JL. Inguinal hernia repair in the perinatal period and early infancy: clinical considerations. J Pediatr Surg 1984;19:832 - 7.

[14] Sheynkin YR, Hendin BN, Schlel PN, et al. Microsurgical repair of iatrogenic injury to the vas deferens. J Urol 1998;159:139- 41.

[15] Lipskar AM, Soffer SZ, Glick RD, Rosen NG, Levitt MA, Hong AR. Laparoscopic inguinal hernia inversion and ligation in female children: a review of 173 consecutive cases at a single institution. J Pediatr Surg. $2010 ; 45(6): 1370-4$.

[16] Klin B, Efrati Y, Abu-Kishk I, Stolero S, Lotan G. The contribution of intraoperative transinguinal laparoscopic examination of the contralateral side to the repair of inguinal hernias in children. World J Pediatr. $2010 ; 6(2): 119-24$

[17] Parelkar SV, Oak S, Gupta R, Sanghvi B, Shimoga PH, Kaltari D, Prakash A, Shekhar R, Gupta A, Bachani M. Laparoscopic inguinal hernia repair in the pediatric age group-experience with 437 children. J Pediatr Surg. 2010 ;45(4):789-92.

[18] Aaron M. Lipskar, Samuel Z. Soffera, Richard D. Glicka, Nelson G. Rosena, Marc A. Levittb and Andrew R. Hong. Laparoscopic inguinal hernia inversion and ligation in female children: a review of 173 consecutive cases at a single institution. J Pediatr Surg. 2010;45(6):1370-1374.

[19] Shalaby R, Ismail M, Dorgham A, Hefny K, Alsaied G, Gabr K, Abdelaziz M. Laparoscopic hernia repair in infancy and childhood: evaluation of 2 different techniques.J Pediatr Surg. 2010 Nov;45(11):2210-6.

[20] Hassan ME, Mustafawi AR.Laparoscopic flip-flap technique versus conventional inguinal hernia repair in children. JSLS. 2007 Jan-Mar;11(1):90-3.

[21] Esposito C, Montinaro L, Alicchio F, Savanelli A, Armenise T, Settimi A. Laparoscopic treatment of inguinal hernia in the first year of life. J Laparoendosc Adv Surg Tech A. $2010 ; 20(5): 473-6$.

[22] Nah SA, Giacomello L, Eaton S, Coppi PD, Curry JI, Drake DP, Kiely EM, Pierro A. Surgical Repair of Incarcerated Inguinal Hernia in Children: Laparoscopic or Open? Eur J Pediatr Surg. 2010 Oct 11. [Epub ahead of print]

[23] Sneider EB, Jones S, Danielson PD. Refinements in selection criteria for pediatric laparoscopic inguinal hernia repair. J Laparoendosc Adv Surg Tech A. 2009 Apr;19(2):237-40.

[24] F. Schier, Laparoscopic inguinal hernia repair - a prospective personal series of 542 children, J Pediatr Surg. 2006;41: 1081-1084 
[25] F.Schier, P.Montupet and C.Esposito et al. Laparoscopic inguinal herniorrhaphy in children: a 3 centre experience with 933 repairs, J Pediatr Surg. 2002;37(3): 395-397. 


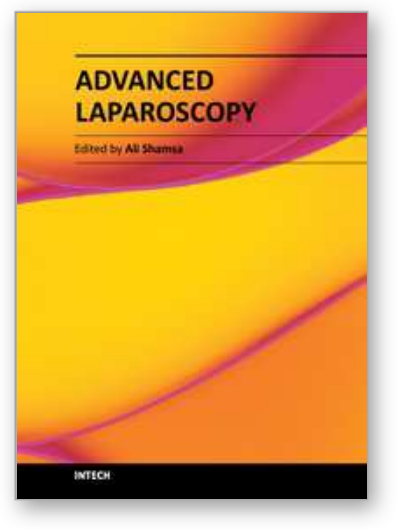

\author{
Advanced Laparoscopy \\ Edited by Prof. Ali Shamsa
}

ISBN 978-953-307-674-4

Hard cover, 190 pages

Publisher InTech

Published online 30, September, 2011

Published in print edition September, 2011

The present book, published by InTech, has been written by a number of highly outstanding authors from all over the world. Every author provides information concerning treatment of different diseases based on his or her knowledge, experience and skills. The chapters are very useful and innovative. This book is not merely devoted to urology sciences. There are also clear results and conclusions on the treatment of many diseases, for example well-differentiated papillary mesothelioma. We should not forget nor neglect that laparoscopy is in use more extensively than before, and in the future new subjects such as use of laparascopy in treatment of kidney cysts, simple nephrectomy, pyeloplasty, donor nephrectomy and even robotic laparoscopy will be researched further.

\title{
How to reference
}

In order to correctly reference this scholarly work, feel free to copy and paste the following:

Yaron Armon and Dan Arbell (2011). Laparoscopic Hernia Repair in Neonates, Infants and Children, Advanced Laparoscopy, Prof. Ali Shamsa (Ed.), ISBN: 978-953-307-674-4, InTech, Available from:

http://www.intechopen.com/books/advanced-laparoscopy/laparoscopic-hernia-repair-in-neonates-infants-andchildren

\section{INTECH}

open science | open minds

\section{InTech Europe}

University Campus STeP Ri

Slavka Krautzeka 83/A

51000 Rijeka, Croatia

Phone: +385 (51) 770447

Fax: +385 (51) 686166

www.intechopen.com

\section{InTech China}

Unit 405, Office Block, Hotel Equatorial Shanghai

No.65, Yan An Road (West), Shanghai, 200040, China

中国上海市延安西路65号上海国际贵都大饭店办公楼 405 单元

Phone: +86-21-62489820

Fax: +86-21-62489821 
(C) 2011 The Author(s). Licensee IntechOpen. This chapter is distributed under the terms of the Creative Commons Attribution-NonCommercialShareAlike-3.0 License, which permits use, distribution and reproduction for non-commercial purposes, provided the original is properly cited and derivative works building on this content are distributed under the same license. 